\title{
E-learning Benchmarking Survey: A Case Study of University Utara Malaysia
}

\author{
Thi Lip Sam \\ College of Business, University Utara Malaysia, Malaysia
}

Copyright $(2015$ Horizon Research Publishing All rights reserved.

\begin{abstract}
E-learning has emerged as a new paradigm in today's education. Many e-learning applications have been developed to meet the increasing demand by education institutions. Previous research mainly focused on a variety of factors that influence the uptake of e-learning. However, very little is known about the quality and the extent of usage of these applications among end users. This study presents results that contain information on the uptake and use of e-learning. The uptake of e-learning is measured by the extent to which different technologies were used by students. A mail survey was conducted to examine the uptake of e-learning among undergraduates. The respondents for this study comprised of 419 respondents representing $16.8 \%$ from a random sample size of 2500 students. Thirty four applications available from Universiti Utara Malaysia Learning information system (Learningzone) were grouped into six categories that served as e-learning benchmarks to assess the uptake of e-learning among undergraduates. The results show that accessing for course materials, communications, viewing information are the commonly used applications while helpdesks and support, and link to other centres are least popular among undergraduates.
\end{abstract}

Keywords E-learning, Learning Management System, Benchmarks, Quality Assurance

\section{Introduction}

The rapid growth of information technology has influenced the way which education is being delivered today. Due to the exponential growth of the internet and web technologies, e-learning has emerged as the new paradigm in modern education. The advantages of e-learning is a plenty that includes; freeing interactions between learners and instructors, or between learners and learners and, from the constraints of time and space. Other benefits of e-learning include providing learning opportunities to all at a reduced cost and increased access to learning opportunities for disadvantaged groups due to physical and geographical barriers. These are significant drivers, especially for adult learners who wish to keep their jobs and further their studies at any institutions with the use of modern technologies. Hence, Education institutions need to invest or enhance their e-learning capacities and capabilities to keep in pace with the rapidly changing teaching and learning pedagogy. Many institutions such as universities have placed a lot of attention to introduce advanced technologies in their respective institutions for teaching and learning purposes.

However, investments to develop LMS or e-learning infrastructure and course contents are costly. Furthermore, Web 2.0 technologies such as podcasting, web-based authoring tools, wikis, real simple syndication (RSS) and other social networking tools are widely available to individuals. The emergence of myriad web 2.0 tools and continued usage of legacy technologies have created questions about the effectiveness and efficiency of these technologies. Subsequently, studies on the performance, quality, usage and benchmarking of e-learning have attracted the interest of researchers [9].

Benchmark creates a standard or reference point and it is generally defined as the criterion by which something is measured, scored or judged. Benchmarking for e-learning have been developed internationally [40]. However, benchmarking of e-learning is very much in infancy phase. Various benchmarks are being developed and adopted by various researchers. Examples such as benchmarking of virtual campuses in Europe and, CHIRON that refers to the project on innovative technological solutions for ubiquitous learning. Other worldwide e-learning benchmarking initiatives are also being introduced by Europeon nations, Australia and United States.

This study will examine the usage of e-learning applications based on a set benchmarks adapted from an Australian Case Study conducted by Flexible Learning Advisory Group (FLAG). It has identified over 250 indicators for e-learning in an environmental scan of Australian education agencies.

The objective of this study namely is to examine the nature and the uptake of e-learning applications. A set of 34 indicators from UUM learning management system or the Learningzone were categorised into six categories namely; Course Content, Communication, Discussion/Forum, View, 
Helpdesk/Support and Link-To, that provide the basis of benchmarking for this study will be examined.

\section{Literature Review}

E-learning is defined as web-based learning which utilises web-based communication, collaboration, multimedia, knowledge transfer, and training to support learners' active learning without the time and space barriers [29]. More often, the term e-learning is also synonymous to the used of information and communication technology (ICT) in the area of education. It is also known as computer support instruction, online education or computer-aided education $[34,19]$.

[49] highlighted that e-learning has a wide range of learning strategies and technologies from the use of CD-ROMS, live audio/video-conferencing, TV lectures, live chat, discussion forums, course announcements and virtual education based on web semantics. Components of e-learning comprised of content delivery in multiple formats, management of the learning experience, and a networked community of learners, content developers and other information system experts who worked in tandem to enable e-learning. E-learning is used to describe the use of any electronic means in the area of education. [21] described this mode of learning as internet enabled learning. Hence, it is expected that the quality and effectiveness of internet based learning have attracted the attention of researchers and policy makers. Quality assurance for e-learning is vital to enable this mode of learning achieved its objectives.

Benchmarking is a quality assurance approach originates from a business and management context. It is a process for improving performance by constantly identifying, understanding and adapting best practices from inside and outside of company. It is focusing on the best practices by means of self-evaluation, including gathering systematic data and information from predefined benchmarks and subsequently formulates the road maps to achieve these benchmarks [16]. Despite limited information about e-learning benchmarks, many institutions of higher learning are proceeding with the implementation of e-learning with the view to improve students' learning experience thereby improving learning performance. Hugh investment in e-learning technologies were aimed at improving quality and access, fostering innovation and increase flexibility in providing learning services to students [9]. Benchmarking information could be used to identify areas that are well accepted by students or clients and those that are limited and in need of improvement.

Benchmarking has been developed into an essential tool for organisations and it is a vital component of good management practice. Many attempts for e-learning quality assurance schemes have been developed internationally by European Centre for Strategic Management of Universities (EMSU), Benchmarking e-learning: Embedding Learning Technologies Institute (ELTI) and VET E-Learning Strategy in Australia. Unfortunately, there is limited national initiatives being carried out in Malaysia other than individual effort among institutions of higher learning and the concept of quality in e-learning studies has been discussed and managed in a disjointed manner.

In their studies on benchmarking, [41] highlighted key benchmark components that include institutional support, course deployment, course structure, student support, faculty support, evaluation and assessment. Since then, comprehensive reviews on benchmarking have been published by [4] and [43].

The European Association of Distance Teaching Universities (EADTU) presented e-learning benchmarking that covers three areas namely, management, products and services. These are in congruence with benchmarking framework by[20], [46] and E-Learning Quality model (ELQ model) [35].

According to Dublin [13], to ensure e-Learning is used by individuals, it needs to provide a learning solution and drive study performance. [17] highlighted that six key factors that underpinned e-learning uptake namely by delivering what learner needs, putting learners at the heart of learning, providing high quality content and technology, support from top management, providing proactive support through communication, promotion and marketing and, creating organisations that values learning.

\section{Methodology}

A questionnaire survey was used to gather data for this study. Personalised cover letters and addresses were used to explain the purpose of the study to the responsents. The respondents were requested to return the questionnaires using the stamped returned enveloped provided. The respondents were given a duration of two weeks to respond to the survey.

The population for this study comprised of undergraduates from University Utara Malaysia. A random sample size of 2500 students was selected for this study. A sample size of 419 responses representing $16.8 \%$ usable questionnaires were returned and subsequently used for data analysis.

The instrument for this survey comprised of items that provide indicators for benchmarking e-learning uptake. The items for LMS applications uptake are derived from UUM Learningzone that comprised of two menus namely the Main Menu and the Course Menu. Section A, obtained information about respondents background; Section B, comprised of items that gather information about the usage of applications in the Main Menu and; Section C, solicit information about the usage of Specific Content Menu in the Learningzone.

A set of 34 indicators derived from UUM Learningzone that were grouped into; Course, Communication, Discussion/Forum, View, Helpdesk/Support and Link To. The items measure the adoption of e-learning through its uptake and use. The measures are based on a four-point ordinal measures ranging from 'Not using' to 'Use all the 
times' to indicate the frequency and sophistication of use by students.

\section{Findings}

\section{Respondents Profile}

Slightly more than two-third of the respondents are females $(76.1 \%)$ while male respondents consisted of a quarter of the sample (23.9\%). The gender composition reflects the student population trend in institutions of higher learning whereby female students formed the majority of the student enrollment (refer to Table 1).

Table 1. Gender

\begin{tabular}{|c|c|c|}
\hline Gender & Frequency & Percent \\
\hline Male & 100 & 23.9 \\
\hline Female & 319 & 76.1 \\
\hline Total & 419 & 100 \\
\hline
\end{tabular}

Table 2 shows more than half of the student sample comprised of second year student $(57.7 \%)$. This is followed by first year student $(25.3 \%)$ and, third or final year students consist of 17 percent of the sample (refer to Table 2).

Table 2. Year of Study

\begin{tabular}{|c|c|c|}
\hline Year of Study & Frequency & Percent \\
\hline First year & 106 & 25.3 \\
\hline Second year & 242 & 57.7 \\
\hline Third / Final year & 71 & 17.0 \\
\hline Total & 419 & 100 \\
\hline
\end{tabular}

\section{Frequency and Duration of Accessing Learningzone}

Table 3 indicates nearly half of the respondents (43.2\%) accessed Learningzone a few times a week. Respondents who accessed Learningzone few times a month is about 30 percent of the total number of respondents. Only 27.2 percent of the respondents have accessed Learningzone on a daily basis.

Table 3. Frequency Accessing Learningzone

\begin{tabular}{|c|c|c|}
\hline Frequency accessing Learningzone & Frequency & Percent \\
\hline Daily & 114 & 27.2 \\
\hline Few times a week & 181 & 43.2 \\
\hline Few times a month & 124 & 29.6 \\
\hline Total & 419 & 100 \\
\hline
\end{tabular}

In terms of average duration spend each time the respondents accessing the Learningzone, only 5 percent of the respondents had spent more than 1 hour. Nearly two third $(71.8 \%)$ spent between 15 minutes to an hour accessing Learningzone. While the remaining 23.2 percent of the respondents stated they had spent 15 minutes or less each time when they logged into Learningzone.
Table 4. Duration Spend at Learningzone

\begin{tabular}{|c|c|c|}
\hline Duration & Frequency & Percent \\
\hline Less than 15 minutes & 97 & 23.2 \\
\hline 15 minutes to 30 minutes & 167 & 39.8 \\
\hline 31 minutes to an hour & 134 & 32.0 \\
\hline An hour or more & 21 & 5.0 \\
\hline Total & 419 & 100 \\
\hline
\end{tabular}

\section{Uptake of Learningzone Main Menu}

In order to capture the extent of Learningzone applications usage, four measures were adopted to operationalize the extent of usage which ranges from 1 (Not using) to 4 (Used all time). Results from Table 5 indicate Google Search has the highest mean score usage 2.82 that reflect the most popular application used by the respondents, followed by View Discussion (2.25), Post Information (2.08), and View Learningzone User Manual (2.07). Other applications with mean score of 2.0 and above are Link to UUM COB website (2.05), Comment and Suggestion in Forum (2.02), Link to UUM Computer Centre (2.02), View New Events (2.02), View Forum (2.01) and Link to UUM UMIS. Learningzone application with the lowest mean score (1.73) is View FAQ.

Table 5. Usage of Learningzone Main Menu

\begin{tabular}{|c|c|}
\hline Applications & Mean \\
\hline View FAQ & 1.73 \\
\hline Google Search & 2.82 \\
\hline \multicolumn{2}{|l|}{ Discussion Room } \\
\hline View Discussion & 2.25 \\
\hline Post Information & 2.08 \\
\hline Participate in Chat/Chat Room & 1.96 \\
\hline \multicolumn{2}{|l|}{ Students' Corner } \\
\hline View Learningzone User Manual & 2.07 \\
\hline View Turnitin Guide & 1.97 \\
\hline \multicolumn{2}{|l|}{ Learningzone Support } \\
\hline Contact Learningzone Helpdesk & 1.84 \\
\hline Post Comment and Suggestion on Learningzone & 1.90 \\
\hline \multicolumn{2}{|l|}{ Update Event } \\
\hline View Learningzone Calendar & 1.89 \\
\hline View New Events & 2.02 \\
\hline \multicolumn{2}{|l|}{ Participate } \\
\hline View Forum & 2.01 \\
\hline Comment and Suggestions in Forum & 2.02 \\
\hline \multicolumn{2}{|l|}{ Link To } \\
\hline UUM COB & 2.05 \\
\hline UUM CAS & 1.98 \\
\hline UUM COLGIS & 2.00 \\
\hline UUM UTLC & 1.94 \\
\hline UUM Library & 1.96 \\
\hline UUM Computer Centre & 2.02 \\
\hline UUM UMIS & 2.00 \\
\hline
\end{tabular}


Social media is increasingly popular being adopted by society. Facebook, Tweeter, LinkedIn and blogs are popular social media tools for posting information, communication, discussion and sharing information. Some of these tools have been provided in the Learningzone albeit in a simplified manner unlike those provided by Facebook, LinkedIn, Tweeter and microblogs. The mean value for Posting Information at Learningzone is 2.08. Respondents' participation on Chat with mean usage value of 1.96. As for View Forum the mean value is 2.01 and Post Comment in Forum with mean value of 2.0. Finally, the mean usage value for Post Comment in Forum is 2.02.

Student Corner and Learningzone Support are developed to assist students to use the Learningzone. Tools that are available for these purposes are User Manual, Turnitin Guide, Helpdesk and, Post Comment and Suggestion. The mean usage value for User Manual is 2.07, Turnitin Guide 1.97, Helpdesk 1.84 and, Post Comment/Suggestion 1.90. In order for students to keep track of events and activities organized by the university, tools such as Learningzone Calendar and View New Events are provided. The mean usage values for these two tools are 1.89 (Learningzone Calendar) and 2.02 (View New Events).

Students often accessed other websites via links provided in the Learningzone. These links include websites of the three colleges; namely COB, CAS, and COLGIS, University Teaching and Learning Centre (UTLC), University Library, Computer Centre and UMIS. The results from Table 6 indicate that the mean usage for Link to $\mathrm{COB}$ website by respondents is (2.05), CAS (1.98) and COLGIS (2.0). The mean usage value for Link to UTLC is 1.94 , Link to UUM Library 1.96, Computer Centre 2.02 and UMIS 2.00.

\section{Uptake of Learningzone Specific Content Applications}

Learningzone specific content consists of My Course whereby students could access course materials and interacting with fellow course mates and course instructors. Some applications available are access to instructors' material such as power point slides, communicate with course instructors and course mates via email messages, participate in forum, blogs, update personal profile, view course mate's profile, view exam grades and subject/subject registered.

Table 6 indicates the usage of all fourteen Learningzone applications for Specific Content had mean scores of above 2.0. The highest mean score is View Course/Subject Registered (2.23), View Exam Grades (2.22), Download Text/Documents/Power Point Slides (2.15), Sending Personal Message to Course Mates (2.15) and Sending Personal Message to Course Instructors (2.13), Post Messages to Course Mates (2.11) and Post Messages to Instructors (2.11). View and Post Blog and, View and Post Forum had mean scores of below (2.05). These results also indicate that respondents' frequent usage of applications in the Specific Content page compared to Main Menu page at Learningzone.
Table 6. Learningzone Specific Content Usage

\begin{tabular}{|c|c|}
\hline Applications & Mean \\
\hline Download Text/ Documents/ Power Point Slides & 2.15 \\
\hline View Course/Subject Registered & $2.23^{*}$ \\
\hline Sending Personal Message to Instructors & 2.13 \\
\hline Sending Personal Message to Course Mates & 2.15 \\
\hline Post messages to Instructors & 2.11 \\
\hline Post Messages to Course Mates & 2.12 \\
\hline Post Blogs & 2.04 \\
\hline View Blogs & 2.01 \\
\hline Update Personal Profiles & 2.07 \\
\hline Post Forum & 2.01 \\
\hline View Forum & 2.03 \\
\hline View News or Announcement & 2.12 \\
\hline View Exam Grades & $2.22 *$ \\
\hline View Course Mate Profiles & 2.08 \\
\hline
\end{tabular}

\section{Indicators for Benchmarking E-Learning in UUM}

Thirty four (34) applications from UUM Learningzone that serve as indicators for e-learning uptake were examined. These indicators provide information on six (6) areas of interest:

\section{(i) Uptake and use of UUM Learningzone for accessing course resources}

Applications in this category including downloading text, document, webpage file and, power point slides. The only application in this category that enable students to download text and document, webpage file, power point slides. The mean usage value for this application is perceived to be high with a value of more than 2 .

\begin{tabular}{|c|c|}
\hline Applications & Mean \\
\hline Download text, documents, power point slides & 2.15 \\
\hline
\end{tabular}

\section{(ii) Uptake and use of UUM Learningzone for communication}

Applications include sending messages to Instructors and classmates. Two applications to communicate with instructors and fellow course mates are also available. The mean usage for these applications is above 2 from a scale of 1 to 4 .

\begin{tabular}{|c|c|}
\hline Applications & Mean \\
\hline Sending personal message to Instructors & 2.13 \\
\hline Sending personal message to course mates & 2.15 \\
\hline
\end{tabular}

(iii) Uptake and use of UUM Learningzone for posting information for discussion or forum

Applications such as post information, participate in Chat room, post comments, post in blogs and forum. The mean usage of applications to post information and discussions are 
above 2 except for participation in chat.

\begin{tabular}{|c|c|}
\hline Main Menu & Mean \\
\hline Post Information & 2.08 \\
\hline Participate in Chatroom & 1.96 \\
\hline Comment/Suggestion in Forum & 2.02 \\
\hline Post blogs & 2.04 \\
\hline Update personal profiles & 2.07 \\
\hline Post forum & 2.01 \\
\hline Post messages to Instructors & 2.11 \\
\hline Post messages to course mates & 2.12 \\
\hline
\end{tabular}

(iv) Uptake and use of UUM Learningzone for viewing

Applications including View Discussions, Learningzone User Manual, Turnitin Guide, Calendar, New Events, View Forum, View Course/Subject Registered, View Blogs, News or Announcement, View Exam Grades and View Course Mate Profiles. A majority of the applications have mean usage values of above 2, except for View FAQ, Calendar and Turnitin Guide.

\begin{tabular}{|c|c|}
\hline Main Menu & Mean \\
\hline View FAQ & 1.73 \\
\hline Google Search & 2.82 \\
\hline View Discussion & 2.25 \\
\hline Learningzone User Manual & 2.07 \\
\hline Turnitin Guide & 1.97 \\
\hline Calendar & 1.89 \\
\hline New Events & 2.02 \\
\hline View Forum & 2.01 \\
\hline View Course/Subject Registered & $2.23 *$ \\
\hline View Blogs & 2.01 \\
\hline View Forum & 2.03 \\
\hline View News or Announcement & 2.12 \\
\hline View Exam Grades & $2.22^{*}$ \\
\hline View Course Mate Profiles & 2.08 \\
\hline
\end{tabular}

(v) Uptake and use of UUM Learningzone on helpdesk/support

Applications include Helpdesk, Post Comment/Suggestion about Learningzone. The mean usage values for helpdesk/support and suggestion are less the 2 that implied these two applications are not frequently used by respondents compared to other applications.

\begin{tabular}{|c|c|}
\hline Applications & Mean \\
\hline Learningzone Helpdesk & 1.84 \\
\hline Post Comment/Suggestion about Learningzone & 1.90 \\
\hline
\end{tabular}

(vi) Uptake and use of UUM Learningzone for Link to other centres

These applications include link to various websites namely COB, CAS, COLGIS, UTLC, Library, Computer
Centre and UMIS. Applications to Link with other UUM websites were examined. Website that link via Learningzone that have mean values of above 2 are Link to COB, COLGIS, Computer Centre and UMIS.

\begin{tabular}{|c|c|}
\hline Applications & Mean \\
\hline Link to COB & 2.05 \\
\hline Link to CAS & 1.98 \\
\hline Link to COLGIS & 2.00 \\
\hline Link to UTLC & 1.94 \\
\hline Link to Library & 1.96 \\
\hline Link to Computer Centre & 2.02 \\
\hline Link to UMIS & 2.00 \\
\hline
\end{tabular}

\section{Discussion and Conclusions}

This study is aimed to assess the uptake of e-learning against a set of benchmarks for e-learning. Based on the six benchmarks adapted from an Australian study, the uptake and use of e-learning to View Discussion (mean score 2.25), Course Registered (2.23) and Exam Grades (2.22), indicated the popularity of these three applications. The uptake of other view applications such as to View News or Announcement (2.12), User Manual (2.07) and New Events (2.02) are perceived to be satisfactory. The applications for viewing that are less popular are View FAQ, Calendar and Turnitin Guide with mean scores of $1.73,1.89$ and 1.97 respectively.

The uptake of e-learning for communication purposes is also popular among students. Two-way communications such as Posting Messages or Sending Messages to Instructors (2.15) and Course Mates (2.13) are commonly used by the respondents. However, the channel for two-way communication appears to be limited only to sending and receiving messages via emails.

For the uptake and use of Learningzone for discussion or participating in forum, it appears to be less popular compared to Posting in Forum or Blogs with a mean score of 2.0 for both applications. This may imply that students are more comfortable to communicate via messages rather than participating in group forum and discussions.

The uptake of e-learning applications for the purpose of assessing course/content resources or materials such as downloading documents such as lecture notes and power point slides are also popular with a mean score of 2.15 . This infers that Learningzone serves mainly as content repository in real sense that allow students to access to course reosurces at their convenience.

The most popular link application in the Learningzone is link to Google Search (2.82). Other popular websites that students access via learningzone are academic centres such as College of Business (2.05) and College of Law, Government and International Studies (2.0) and, Computer Centre (2.2). The uptake of applications related to client support services namely, Helpdesk and Posting Suggestion 
to Learningzone have mean scores of 1.84 and 1.9 respectively.

Overall, the findings highlighted the need to relook in particular, applications which have been underutilised such as for the purpose of providing client support. Furthermore, more applications are needed to be incorporated for two-way communication between students and instructors and also among students. Applications for communication only through emails is insufficient. Other Web 2.0 social medias such as Facebook, Tweeter, LinkedIn and blogs ought to be incorporated. Furthermore, the uptake of e-learning for assessing course materials and course resources can further be enhanced as students mainly used Learningzone to assess notes and power point slides. Applications such as podcasts, webinar, RSS and teleconference are some of the applications that could cater for learning and knowledge sharing.

Generally, the findings from this study illustrate that online learning presents opportunities but also a number of challenges to students specifically and the higher education sector broadly. These issues are not new to researchers in the field of online learning research (see for example: $[18,47,37$, $39,24])$.

\section{Managerial Implications}

[10] in a paper titled "E-learning: The hype and the reality" suggests that many believe that e-learning is transforming education. However, she argues that e-learning is still marginal in the lives of most students with technology being used for little more than acting as a content repository. While some applications or tools may assist student learning, nonetheless, online learning environments that restrict themselves only to delivering static resources such as downloading lecture notes and power point slides that do not characterise the quality online learning environments [39]. Furthermore, current practices of e-learning do not take account of learner characteristics which may influence learning.

For online learning to be effective, tertiary education institutions should engage learners as active participants in their learning. Achieving this means offering students opportunities for interaction in ways that can promote change and growth in the learner's conception of knowledge. Such pedagogies aim to encourage students to become autonomous learners, capable of problem solving and critical thinking, and to move them from being passive recipients of information and knowledge to being active, enthusiastic learners and knowledge creators [51]. However, such tools and applications that enable active and students' centered learning are found to be lacking in many e-learning environment. Many instances, the capability and potential of e-learning are restricted due to insufficient bandwidth, Internet speed or other physical barriers.

Education pedagogy is also concerned with building meaningful learning relationships between students and instructors, and students and their peers. It involves encouraging collaboration as well as cooperation in learning.
The appropriation of Web 2.0 technology for teaching provides great opportunities for the promotion of innovative and interactive quality e-learning environments. Some of the pertinent Web 2.0 applications for collaborative learning such as podcasts, wikis, RSS, webinars and social networking tools have not been fully utilized by tertiary institutions' e-learning portals.

\section{Conclusions}

While the major findings of this study indicated evidence of an instructor centred and content focused e-learning approach, nonetheless students willingness to learn and engage more in the online environment cannot be denied. Though, many higher education institutions used information technologies as a key strategic to reducing costs and at the same time to support initiatives in advancing student centred flexible learning, and improving the quality of teaching, however, if the way in which the majority of LMS sites are perceived by students as content depository, the full benefits and potential of LMS are not being achieved.

Students demand more than a repository dump - they required an active and enthusiastic engagement from their teachers. The results indicate that Learningzone is a teacher centred approach online teaching. Though this study did not involve staff, nonetheless, academic staff namely instructors are of key stakeholders to determine the success of LMS.

Universities need to pay more attention to the institution's key stakeholders, students, and support academic staff and to advance the widely recognized potential of online learning. In other words, if academic teaching staff is to engage with technology in ways that encourage them to innovate, then institutions must 'make such efforts to enhance the learning of their students a high priority and back this in practice as well as in their rhetoric [25].

\section{REFERENCES}

[1] Abdullah, M. M.B., Koren, S. F., Muniapan, B., \& Rathakrishnan, B. (2008). Adult participation in self-directed learning programs, International Education Studies, 1 (1), 66-72.

[2] Alexander, S. (2001). E-learning Developments and Experiences. Education and Training, 43(4), 240-248.

[3] Anderson, T. \& Elloumi T. (ed.) (2011). The Theory and Practice of Online Learning. Edmonton: AU Press.

[4] Bacsich, P. (2011). Bibilography of Benchmarking. URI: http:// www.virtualcampuses.eu/index.php/bibliography_of benchmarking. Cited 08/08/2012.

[5] Bates, T. (2005). Technology, E-learning and Distance Education. London: Routledge.

[6] Ceobanu, C., Criu, R., \& Asandului, L. (2009). A theoretical framework for quality indicators in e-learning. Journal of Distance education, 19(4), 126-135.

[7] Chang, S. \& Tung, F. (2008). An empirical investigation of 
students' behavioural intention to use the online learning course website. British Journal of Education Technology, 39(1), 71-83.

[8] Chen, Y. S., Kao, T. C., \& Sheu, J. P. (2005). Realising outdoor independent learning with butterfly-watching mobile learning system. Journal of Educational Computing Research, 33(4), 395-417.

[9] Choy, S. (2007). Benefits of e-learning benchmarks: Australian Case Studies. The Electronic Journal of E-Learning, 5(1), 11-20.

[10] Conole, G. (2004). E-learning: The hype and the reality. Journal of Interactive Media in Education, http://www-jime.open.ac.uk/2004/12/

[11] Davis, J. F., Sauber, M. H., \& Edwards, E. A. (2011). Managing quality in online education: A conceptual model for program development and improvement. International Journal of Management in Education, 5(1), 93-118.

[12] Dodd, C., Kirby, D., Seifert, T., \& Sharpe, D. (2009). The impact of high school distance e-learning experience on rural students' university achievement and persistence. Distance Learning Administration, 7(1), 77-86.

[13] Dublin, L. (2004). The nine myths of e-learning implementation: Ensuring the real return on your e-learning investment. Industrial and Commercial Training, 36(7), 291-294.

[14] Ellis, R. A., Jarkey, N., Mahony, M. J., Peat, M., \& Sheely, S. (2007). Managing Quality Improvement of E-Learning in a Large, Campus- based University. Quality Assurance in Education, 15(1), 9-23.

[15] El-Seoud, S. A., Al-Khasawneh, B., \& Awajan, A. (2007). Using Web-Based Course to Enhance Educational Process at Jordan Universities - A Case Study. Paper presented at the ICL.

[16] ENQA. (2009). Standards and Guidelines for Quality Assurance in the European Higher Education Area. Helsinki, ENQA.

[17] Ettinger, A., Holton, V., \& Blass, E. (2005). E-learners ecperience: Learning from the pioneers. Industrial and Commercial Training, 37(6), 286-290.

[18] Evans, T. \& Nations, D. (2000). Understanding changes to university teaching. In T. Evans \& D. Nations (Eds.), Changing university teaching: Reflections on creating educational technologies. Kogan Page, London, 160-175.

[19] Fallon, C. \& Brown, S. (2003). E-learning Standards: A Guide to Purchasing, Developing, and Deploying Standards-Conformant E-Learning. Delray Beach, FL: St. Lucie.

[20] Frydenberg, J. (2002). Quality standards in e-learning: a matrix analysis. The International Review Research in Open Distance Learning, 3(2), 88-101.

[21] Gunasekaran, A., McNeil, R. D., \& Shaul, D. (2002). E-learning research and application. Industrial and Commercial Training, 32(2), 44-53.

[22] Halawi, L. A., Pires, S. \& McCarthy, R. (2009). An Evaluation of E-Learning on the Basis of Bloom's Taxonomy: An Exploratory Study. Education for Business, 84(6), 374-380.
[23] Hayen, J. Cappel, J. \& Roger, L. (2004). Evaluating e-learning: A case study. Journal of Computer Information Systems, 44(1), 49-56.

[24] Holt, D. \& Challis, D. (2007). From policy to practice: One university's experience of implementing strategic change through wholly online teaching and learning. Australia Journal of Educational Technology, 23(1), 110-131.

[25] Hannan, A. (2005). Innovating in higher education for change in learning technology. British Journal in Education Technology, 36(6), 975-985.

[26] Jebeile, S., \& Reeve, R. (2003). The diffusion of e-learning innovations in an Australian secondary college: strategies and tactics for education leaders. The Innovation Journal, 77-82.

[27] Jihad, A. A. \& Sondos, A. A. (2006). The impact of applying IT and e-learning in Economic Information Systems. American Journal of Applied Sciences, 3 (2), 1722-1725.

[28] Lau, E. K. W. (2009). The institutional effect on e-learning in Hong Kong. Computer Society, 88(7), 1529-1541.

[29] Lee, B. C., Yoon, J.O., \& Lee, I. (2009). Learners' acceptance of e-learning in Korea: Theories and results. Computer in Education, 53(4), 1320-1329.

[30] Lin, C. C., Ma, Z., \& Lin, R.C.P. (2011). Re-examining the critical success factors of e-learning from the EU perspective. International Journal of Management in Education, 5(1), 44-62.

[31] Marshall, S. (2012). Improving the quality of e-learning: Lessons from eMM. Journal of Computer Assisted Learning, 28 (1), 65-78.

[32] Meyer, K. A. (2002). Quality in distance education: Focus on-line learning. San Francisco: Jossey Bass.

[33] Mistry, V. (2008). Benchmarking e-learning: Trailing the MIT90s framework. Benchmarking: An International Journal, 15(3), 326-340.

[34] Mutula, S. M. (2002), University education in Kenya: current developments and future Outlook. International Journal of Educational Management, 16(3) 109-119.

[35] NAHE. (2011). Quality assurance. URI: http;//www. hsv.se/ kvalitet/ Cited 14/7/2012.

[36] Olaniran, B. A. (2006). Applying synchronous computer-mediated communication into course design: Some considerations and practical guides. Campus Wide Information Systems, 23(1), 210-220.

[37] Naidu, S. (2004). Trends in faculty use and perceptions of eLearning. Asian Journal of Distance Education, 2(2), 23-35.

[38] Ng, K. C. (2007). Replacing face-to-face tutorials by synchronous online technologies: Challenges and pedagogical implications. International Review of Research in Open and Distance Learning, 8(1), 1-15.

[39] Oliver, R. (2005). Quality assurance and e-learning: Blue skies and pragmatism. ALT-J: Research in Learning Technology, 13(3), 173-187.

[40] Ossiannilsson, E. (2012). Benchmarking E-Learning in Higher Education: Lessons Learned from International Project. Unpublished Ph. D. Dissertation, University of Oulu, Finland. 
[41] Phipps R \& Merisotis, J. (2000). Quality on the line: Benchmark for Success in Internet-based Distance Education. Washington DC: Institute for Higher Education Policy.

[42] UNESCO. (2010). UN Summit on the millennium development goals. URI:

http://www.un.org/en/mdg/summit2010/pdf/mdg\%20outcom e \%20documentpdf. Cited 08/06/2011.

[43] Re. ViCa (2009). Bibliography of benchmarking. URI:http://www.virtualcampuses.eu/index.php/bibliography _of_benchmarking. Cited 07/06/2011.

[44] Sarsa, J. \& Soler, R. (2012). E-learning quality: Relations and perceptions. Information and Communication Technology Education, 8(2), 46-60.

[45] Selim, H. (2007). Critical success factors for e-Learning acceptance: Confirmatory factor models. Computer in Education, 49(1), 76-83.

[46] Shelton, K. (2011). A review of paradigms for evaluating the quality of online education programs. In Mc Cracken H (ed.) Focus on Adult Learning Through Inquiry. URI:http://hollymaccraken:wordpress. com/2011/04/09/a-review-of paradigms-for-evaluating-the-qualityof-online-education-programs/Cited 2011/07/07.

[47] Spratt, C. (2003). Technology innovators and structures of indifference in higher education. $16^{\text {th }}$ Conference Proceedings: Sustaining Quality Learning Environments, Open and Distance Learning Association of Australia, Canberra, 1-3 October.

[48] UNESCO. (2010). UN Summit on the millennium development goals.

URI:http://www.un.org/en/mdg/summit2010/pdf/mdg\% 20outcome\%20documentpdf. Cited 08/06/2011.

[49] Urdan, T., \& Weggen, P. (2000). Corporate E-Learning: Exploring a New Frontier. Hambrecht \& Co.

[50] Wang, Q., Zhu, Z., Chen, L., \& Yan, H. (2009). Guest editorial e-learning in China. Campus-Wide Information Systems, 26(1), 77-81.

[51] Weaver, D. (2008). Academic and student use of a learning management system: Implications for quality. Australia Journal of Educational Technology, 24(1), 30-41. 